Article

\title{
Effects of Heat Treatment and Tea Polyphenols on the Structure and Properties of Polyvinyl Alcohol Nanofiber Films for Food Packaging
}

\author{
Jinjie Luo ${ }^{1,2,3, *}$, Duquan Zuo ${ }^{1,2}$, Zhenghua Deng ${ }^{1,2}$, Anping Ji ${ }^{1,2}$ and Guofeng Xia ${ }^{1,2}$ \\ 1 College of Mechanical Engineering, Chongqing Three Gorges University, Chongqing 404000, China; \\ taiyanghefeng@126.com (D.Z.); dzh1017@126.com (Z.D.); japmail712@163.com (A.J.); \\ xiaguofeng@sanxiau.edu.cn (G.X.) \\ 2 Chongqing Engineering Technology Research Center for Light Alloy and Processing, Chongqing Three \\ Gorges University, Chongqing 404000, China \\ 3 School of Materials Science and Engineering, Southwest Jiaotong University, Chengdu 610031, China \\ * Correspondence: luoke1949@126.com
}

Received: 2 November 2019; Accepted: 26 December 2019; Published: 5 January 2020

\begin{abstract}
In this study, biodegradable polyvinyl alcohol (PVA) was blended with natural antioxidant tea polyphenols (TPs) to produce PVA/TP nanofiber films by electrospinning. The effects of heat treatment and TP incorporation on the structural and physical properties of the films were then evaluated. Scanning electron microscopy (SEM) and Fourier transform infrared spectroscopy (FTIR) revealed that the PVA/TP nanofiber film has a more compact structure and better morphology than PVA alone. In addition, the water resistance was enhanced, and the formation of hydrogen bonds between the TP and PVA molecules increased via the heat treatment. Furthermore, the mechanical, antioxygenic, and antibacterial properties of the nanofiber films were significantly improved $(P<0.05)$ owing to the incorporation of TP. In particular, when the mass ratio of the PVA/TP was 7:3, the elongation at break (EAB) of the film increased to $105.24 \% \pm 2.87 \%$, and the antioxidant value reached a maximum at $64.83 \% \pm 5.21 \%$. In addition, the antibacterial activity of Escherichia coli (E. coli) and Staphylococcus aureus (S. aureus) increased to the maximum levels of $82.48 \% \pm 2.12 \%$ and $86.25 \% \pm$ $2.32 \%$, respectively. In summary, our study produced a functional food packaging material that includes preservation with an acceptable bioactivity, ability to keep food fresh, and biodegradability.
\end{abstract}

Keywords: tea polyphenols; polyvinyl alcohol; heat treatment; water resistance; nanofiber film

\section{Introduction}

Antioxidant food packaging film has strong potential as a packing material owing to its ability to incorporate or immobilize antioxidizing agents to retard the growth of microorganisms and to improve food shelf life [1,2]. Natural antioxidants, which have recently been shown to be safer and healthier than synthetic antioxidants, are possible candidates for active food matrices as active agents incorporated into packaging material. Therefore, the preparation of antioxidant packaging films is of great significance [3].

Polyvinyl alcohol (PVA), a polymer with excellent properties, such as biocompatibility, biodegradability, non-toxicity, chemical resistance and the ability to form a film, is used as an environmentally friendly material for preparing packaging films [4]. The good water solubility and biocompatibility of PVA can be attributed to the existence of hydroxyl groups in the molecular structure. However, their high water solubility also makes PVA films unstable in external environments. To address this limitation, research on modified PVA has been conducted. Current modification methods are usually divided into chemical crosslinking, inorganic nanomaterials in the composite, physical 
crosslinking and polymer blending. Sagnelli et al. [3] proved that blending polymers with other natural products is an effective method for improving the functionality of all-natural bio-plastics systems. Lim et al. [5] developed water-resistant PVA films using crosslinked PVA/polyacrylic acid blends, and reported that the films showed lower oxygen permeability and greater water resistance than PVA alone. Yang et al. [6] prepared PVA/chitosan nanofiber films via electrospinning, which were then crosslinked with glutaraldehyde vapor. The result revealed a dramatic decrease in the swelling ratio, which demonstrates the potential for preparing barrier-resistant, selective films. Nevertheless, the volatilization and residue of the toxic crosslinking agents such as polyacrylic acid and glutaraldehyde are main limitations because they could harm the environment and the integrity of the film over time. Abdolmaleki et al. [7] improved the water resistance of PVA film through a strong interfacial interaction between the graphene oxide of the inorganic nanomaterials and the PVA matrix; however, the higher cost of this method restricted the application of the film. Altough Pirzada et al. [8] synthesized films that were less water-soluble through a mixture of PVA and nano-silica, their properties appeared to be limited by nano-silica aggregation. Noh et al. [9] subsequently used a method of repeating the number of freeze-thawing cycles to improve the degree of crystallinity and water resistance of a PVA film. The water resistance was also enhanced by a different method of physical crosslinking by cast-drying at high temperature, which resulted in the formation of a micrometer-scale fibril network and the appearance of a closed crystalliferous region. However, the complicated cycles limited its wide usage in industrial production. Liu et al. [10] demonstrated the water resistance of a nano- $\mathrm{Fe}_{3} \mathrm{O}_{4} / \mathrm{PVA}$ composite nanofiber that was remarkably enhanced via heat treatment for $2 \mathrm{~h}$ at $140{ }^{\circ} \mathrm{C}$. Lee et al. [11] reported that no changes in the morphology and structure of electrospun $\mathrm{ZnO} / \mathrm{PVA}$ films were observed in the morphology and structure of electrospun ZnO/PVA films after heat treatment at $165^{\circ} \mathrm{C}$ for $10 \mathrm{~min}$ and immersion in water at $18^{\circ} \mathrm{C}$ for $1 \mathrm{~h}$. Xie et al. [12] proposed that heat treatment at $140{ }^{\circ} \mathrm{C}$ favored cross-linking reactions in PVA/maleic acid/tetraethyl orthosilicate, and they also obtained a less hydrophilic membrane. Gao et al. [13] proposed that heat treatment can enhance the water resistance and dye adsorption performance of $\alpha-\mathrm{Fe}_{2} \mathrm{O}_{3} / \mathrm{PVA}$ nanofibers. Cano et al. [14] studied films composed of blended pea starch and PVA, which had a lower water solubility and water sorption as a result of the hydrogen bond formation between the two components. Alpay et al. [15] prepared a water-resistant sulfonated poly ether ketone/PVA composite membrane using a blending method. In their study, the water solubility decreased with the addition of the sulfonated poly ether ketone. Currently, water-resistant PVA films are widely used in separation purification [16], bioartificial tissue engineering [17] and polaroid manufacturing [18]; few studies have focused on the preparation of antioxidant packaging films based on PVA.

In order to expand the applications of antioxidant packaging films, many researchers have added some natural antioxidant substances to PVA, such as tea polyphenol (TP), essential oils, and glutathione. TPs are a type of natural antioxidant extracted from tea leaves and collectively refer to a set of polyphenolic compounds with extremely high antioxidant activity and multiple functions such as anti-cancer and bactericidal effects. Thus, they have been used in the fields of food, medicine, and health care [19]. The aim of the present work is to explore the effects of heat treatment and various TP concentrations on the structure, physical properties, water resistance, antioxidation and antibacterial activity of PVA/TP nanofiber films. The films are prepared by electrospinning after the biodegradable PVA material is blended with naturally antioxidant TPs; distilled water is used as a solvent. The incorporation of TPs endows the films with antioxidant and antimicrobial properties [20], and the formation of the hydrogen bond between the TPs and PVA molecules provides them with a more compact structure with enhanced mechanical properties. Subsequently, the nanofiber films are treated at high temperature by physical crosslinking to improve the water resistance. The nanofiber film with a high specific surface area and macroscopic pore structure resulted in a better hygroscopicity than the casted film [21], because the former provides a better continuous release of antioxidants during storage [22]. These findings detail the optimal formulation of a PVA/TP nanofiber film with suitable performance for food packaging applications. 


\section{Materials and Methods}

\subsection{Materials}

PVA (degree of polymerization, $1788 \pm 50$; deacetylation degree, $\geq 97.0 \%$ ) was purchased from Chengdu Kelong Chemicals Co., Ltd., Chengdu, China. The TP and 2,2-diphenyl-1-picrylhydrazyl (DPPH) were obtained from Shanghai Xinglong Biotechnology Co., Ltd. (Shanghai, China). Staphylococcus aureus ATCC 29523 and Escherichia coli ATCC 25922 were acquired in lyophilized form from China Center of Industrial Culture Collection (CICC), Beijing, China.

\subsection{Fabrication of the PVA/TP Nanofiber Films}

The PVA powder was weighed and dissolved in $40 \mathrm{~mL}$ of deionized water to obtain a $15 \%(w / v)$ PVA solution. Various amounts of TPs were added at mass ratios of PVA and TP at 10:0, 9:1, 8:2, and 7:3, which were denoted as PVA, PVA/TP-9:1, PVA/TP-8:2, and PVA/TP-7:3 respectively. The mixtures were then heated at about $80^{\circ} \mathrm{C}$ for 2 to $3 \mathrm{~h}$ under stirring to produce a homogeneous solution prior to electrospinning.

The solution was subsequently loaded into an inner diameter of $0.7 \mathrm{~mm}$. The ejection flow rate was set to $0.5 \mathrm{~mL} / \mathrm{h}$ via a syringe pump, the voltage was controlled at $20 \mathrm{kV}$, and the distance between the capillary tip and the collector was controlled at $20 \mathrm{~cm}$. The fibers collected were vacuum-dried at $150{ }^{\circ} \mathrm{C}$ for $20 \mathrm{~min}$, and the aforementioned nanofiber films after heat treatment were denoted as PVA/HT, PVA/TP/HT-9:1, PVA/TP/HT-8:2, and PVA/TP/HT-7:3, respectively [12]. Afterward, PVA/HT, PVA/TP/HT-9:1, PVA/TP/HT-8:2, and PVA/TP/HT-7:3 were immersed in a $\%(w / v)$ calcium chloride solution and removed using aluminum foil. The nanofiber films were then cleaned with deionized water to remove residue from the calcium chloride solution. Finally, all the nanofiber films were conditioned at $23{ }^{\circ} \mathrm{C}$ and $50 \%$ relative humidity for $24 \mathrm{~h}$ before testing.

\subsection{Morphology Studies}

The effects of heat treatment and water soaking on the morphologies of the nanofiber films were observed using a SUI510 scanning electron microscope (SEM; SUI510, Hitachi AG, Tokyo, Japan) at a voltage of $10 \mathrm{kV}$. Then, 50 selected images from each sample were selected and the nanofiber film diameters were measured using the software ImageJ (V1.8.0.112) [23].

\subsection{Fourier Transform Infrared Experiment}

The chemical structures of the nanofiber films and the interactions between the PVA and TPs were analyzed using a spectrometer (BOEN, Feierboen Precision Instruments Ltd., Shanghai, China). The samples were identified at a resolution of $4 \mathrm{~cm}^{-1}$ as the average of 32 scans with a range of $4000-650 \mathrm{~cm}^{-1}$ [24].

\subsection{Water Resistance}

Water resistance was evaluated by conducting water solubility (WS) and swelling ratio (SR) tests. To measure the WS, $40 \mathrm{~mm} \times 40 \mathrm{~mm}$ nanofiber film samples were prepared and weighed $\left(W_{0}\right)$ following the method in [25]. The samples were then immersed in distilled water at $25^{\circ} \mathrm{C}$ for $24 \mathrm{~h}$. Undissolved sample portions were subsequently removed from the water and the surface water was removed with filter paper prior to weighing $\left(W_{1}\right)$. The samples were then weighed again $\left(W_{2}\right)$ after drying at $105^{\circ} \mathrm{C}$ for $24 \mathrm{~h}$. Finally, the WS and SR of the samples were determined using the following equations:

$$
\begin{aligned}
& \mathrm{WS}=\frac{W 1-W 0}{W 0} \times 100 \% \\
& \mathrm{SR}=\frac{W 2-W 0}{W 0} \times 100 \%
\end{aligned}
$$




\subsection{Mechanical Properties}

The mechanical strength of the nanofiber films was tested using stress-strain curves to obtain the tensile strength (TS) and elongation at break (EAB), the data for which were collected under room temperature using a tensile testing equipment (HD-B609B-S, Haida Instruments Co., Ltd., Dongguan, China) based on the American Society for Testing and Materials (ASTM) standard D638 [26]. The nanofiber films were cut into $50 \mathrm{~mm} \times 10 \mathrm{~mm}$ rectangular samples prior to measurement. The crosshead speed was $12 \mathrm{~mm} / \mathrm{min}$ according to standard procedures (ASTM standard 882 [27] for thin films and membranes). Five experiments were performed on each sample group.

\subsection{Antioxidant Activity}

The radical-scavenging activities (RSAs) of the nanofiber films were evaluated via the DPPH assay following the method of Jahed et al. [28]. Different nanofiber films equivalent to $25 \mathrm{mg}$ were dissolved in $3 \mathrm{~mL}$ distilled water. Then, $7.8 \mathrm{~mL}$ of a $0.1 \mathrm{mmol} / \mathrm{L}$ methanolic solution of DPPH was mixed with the aforementioned nanofiber film water mixture and the two were allowed to interact for $30 \mathrm{~min}$ in a dark room. Methanol was prepared for the baseline correction and a blank was formed according to the above absence of the extract. Changes in the absorbance of the extract samples were measured at $517 \mathrm{~nm}$ using a spectrophotometer (752N UV-VIS NIR; INESA Analytical Instrument Co., Ltd., Shanghai, China). The RSA was calculated using the following formula:

$$
\text { RSAs }=1-\frac{A s}{A_{\mathrm{DPPH}}} \times 100 \%
$$

where $A_{\mathrm{DPPH}}$ is the absorbance value at $517 \mathrm{~nm}$ of the blank and $A \mathrm{~s}$ is the absorbance value at $517 \mathrm{~nm}$ of the samples.

\subsection{Color and Transparency of the Films}

The color characteristics of the nanofiber films were measured with a color difference meter (CS-10, Shenzhen Baiteng Technology Development Co., Ltd., China) using three parallel samples for each condition [29]. Each sample was measured in triplicate for subsequent analysis. A standard plate was used as the control film, with $L^{*}=90.07 \pm 0.93, a^{*}=2.94 \pm 0.40$, and $b^{*}=-5.33 \pm 0.28$. The total color difference of the nanofiber films was calculated using the following equation:

$$
\Delta E=\sqrt{(\Delta L *)^{2}+(\Delta a *)^{2}+(\Delta b *)^{2}}
$$

The films were cut into sample strips, which were $40 \mathrm{~mm}$ long and $10 \mathrm{~mm}$ wide, and then placed in a quartz cuvette. The whole light transmittance and absorbance spectra were obtained by using an ultraviolet-visible (UV-vis) spectrophotometer (Agilent, Santa Clara, CA, USA) in the range of 200-800 $\mathrm{nm}$ with a scan rate of $250 \mathrm{~nm} / \mathrm{min}$. The transparency value of the films was calculated by using the following equation:

$$
\text { Transparency value }=\log \mathrm{T} 600 / x
$$

where T600 is the fractional transmittance at $600 \mathrm{~nm}$ and $x$ is the film thickness $(\mathrm{mm})$. Higher transparency values represent lower films transparencies. [30].

\subsection{Antimicrobial Experiment}

The nanofiber films were cut into $20 \mathrm{~mm} \times 20 \mathrm{~mm}$ squares. For the antimicrobial experiment, $100 \mathrm{mg}$ samples were placed in a super clean bench for $2 \mathrm{~h}$ UV ray sterilization prior to measurement [31]. Then, E. coli and S. aureus were then inoculated into the $150 \mathrm{~mL}$ culture medium in $250 \mathrm{~mL}$ conical flasks separately and cultured at $37^{\circ} \mathrm{C}$ for $48 \mathrm{~h}$. Next, $1 \mathrm{~mL}$ of the culture medium was added to $9 \mathrm{~mL}$ phosphate buffered saline (PBS), and each film sample was placed in the resultant $10 \mathrm{~mL}$ microbial/PBS solution. The solutions were cultured by shaking at $37^{\circ} \mathrm{C}$ for $24 \mathrm{~h}$. Afterwards, the dilution solutions 
ranging from $1 \times 10^{-5}$ to $1 \times 10^{-7}$ were produced, rapidly plated on nutrient agar and cultured at $37^{\circ} \mathrm{C}$ for $24 \mathrm{~h}$ before the colonies were enumerated. The bacteriostatic rate was obtained using the following equation:

$$
R=\frac{B-C}{B} \times 100 \%
$$

where $R$ is the bacteriostatic rate (\%), B is the average value from the colonies (CFU/g) of the blank control and $C$ is the average value from the colonies (CFU/g) of the nanofiber films.

\subsection{Statistical Analysis}

All data are expressed as mean \pm standard deviation. Analysis of variance (ANOVA) and significance testing were performed using Duncan in statistical analysis software SPSS (V24.0), and mapping was performed with Origin 2018 (V2018).

\section{Results}

\subsection{Diameters and Morphologies of the Nanofiber Films}

In Figure 1a-f, the morphologies of the nanofiber films are shown at 1000, 5000 and 30,000-fold magnification. As indicated in Figure $1 \mathrm{a}-\mathrm{c}$, these showed that the pure PVA nanofiber films exhibited good network structural integrity and smoothness with no cracking or bead defects. When the TP was added, however, the fibers appeared disordered with an increasing degree of crosslinking. Although the nanofiber films exhibited a bead structure and an uneven diameter, the surface of the nanofiber film showed no cracking. No significant difference was noted between the thicknesses of the PVA and PVA/TP-9:1 nanofiber films.
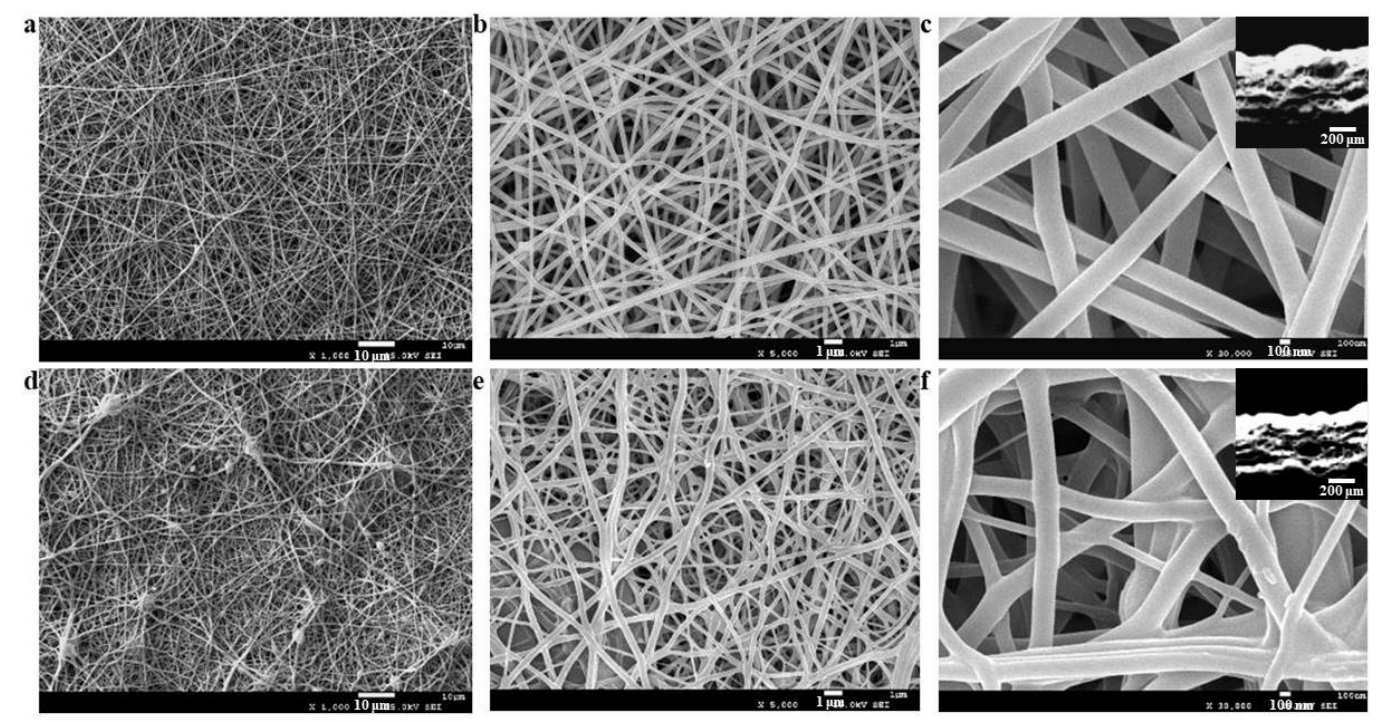

Figure 1. Scanning electron microscope (SEM) images of nanofiber films (a-c) polyvinyl alcohol (PVA); (d-f) nanofiber films PVA/tea polyphenol (TP)-9:1; and (g-h) the diameter distribution of the PVA and PVA/TP-9:1 film.

The average diameter of the electrospun nanofiber was measured using ImageJ. The diameter of the pure PVA nanofiber film was homogenous and ranged from about 250-350 nm with an average diameter of $290 \mathrm{~nm}$. However, the PVA/TP-9:1 nanofiber film showed a heterogeneously spread diameter of 100-500 nm with main distributions at 250-300 nm and 400-450 nm, which is wider than that of the pure PVA nanofiber film, and the average diameter had visibly increased to $310 \mathrm{~nm}$. This can be attributed to the molecular interactions between PVA and TPs, which were greater after the addition of the TP, and to the uneven distribution of the charge resulting from the electrostatic 
spinning instability. In addition, it was obvious that the spinning rate of the pure PVA nanofiber film was obviously higher than that of the nanofiber film; this also demonstrates an increase in the molecular interactions. The thicknesses of nanofiber films were measured from vertical section images and processed by ImageJ software. The thicknesses of pure PVA and PVA/TP-9:1 nanofiber films were around 600 and $700 \mu \mathrm{m}$, respectively, indicating no significantly different thickness between them.

A comparison of Figure $2 \mathrm{a}, \mathrm{b}$ reveals that the fibers had formed a more compact structure with a network morphology, demonstrating that the heat treatment process increased the degree of cross-linking in the component and that the numbers of these hydrogen bonds resulted from the cross-linking of PVA, and TP increased upon heat treatment. Xie et al. [13] obtained similar results in morphology after heating.

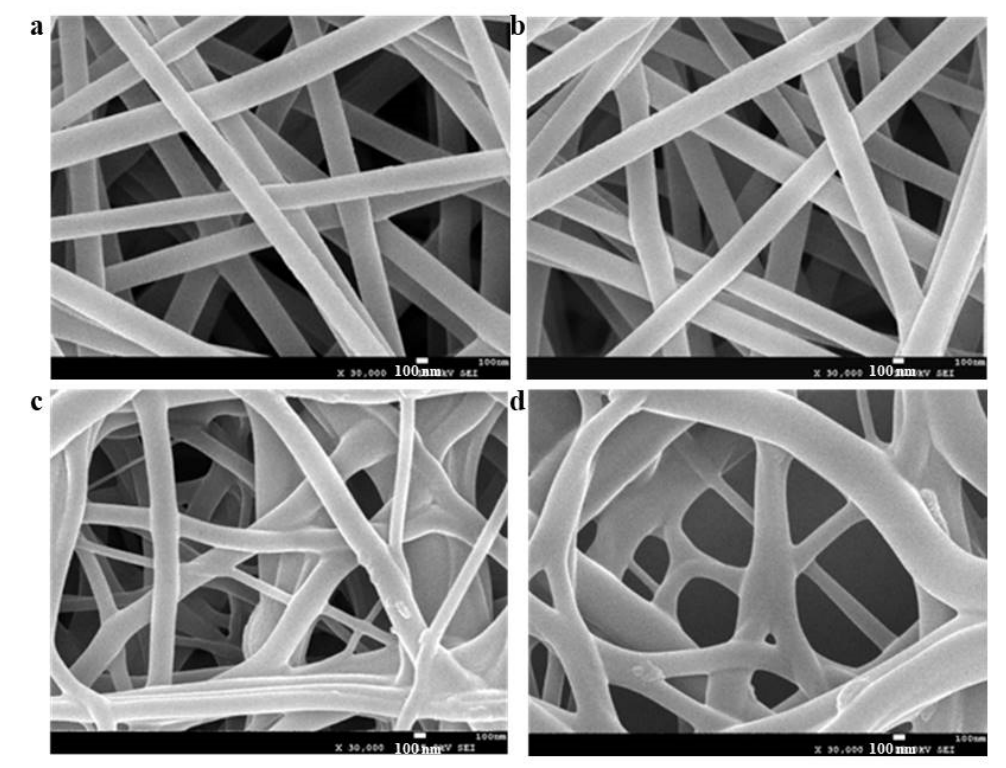

Figure 2. SEM images of nanofiber films: (a) PVA; (b) nanofiber film PVA/heat treatment (HT); (c) nanofiber film PVA/TP-9:1; (d) PVA/TP/HT-9:1 nanofiber films.

\subsection{FTIR Analysis}

Figure 3 presents the characteristic FTIR spectra corresponding to TP, PVA, PVA/HT, PVA/TP-8:2, PVA/TP/HT-8:2, PVA/TP-9:1, and PVA/TP/HT-9:1. For the TP nanofiber films, the bands at 3370 and $1650 \mathrm{~cm}^{-1}$ were caused by the stretching of hydroxyl group and $\mathrm{C}=\mathrm{C}$ bonds, respectively [32]. The characteristic peaks of the PVA were measured at approximately 3292,1086 , and $846 \mathrm{~cm}^{-1}$, with the first peak attributed to the stretching of the $\mathrm{O}-\mathrm{H}$ bonds and the last two attributed to $\mathrm{CH}_{2}$ stretching vibration [33] and a peak caused by $\mathrm{C}-\mathrm{O}$ stretching vibration at $1733 \mathrm{~cm}^{-1}$ [34]. As shown in PVA/TP-9:1 and PVA/TP-8:2, the O-H absorption peaks shifted from $3292 \mathrm{~cm}^{-1}$ in the pure PVA nanofiber films to $3331 \mathrm{~cm}^{-1}$ in the PVA/TP nanofiber films [35]. This indicates the formation of a new hydrogen bond between the TP, and that the addition of TPs strengthened the intensities of the $\mathrm{O}-\mathrm{H}$ absorption peaks, which is consistent with the results reported by Yuan et al. [36]. However, no significant changes were observed in other characteristic peaks for PVA and nanofiber films, which confirms the formation of complexes between TP and PVA as physical blending. The intensities of all absorption peaks showed clear increases, which is attributed to the greater vibrational dipole moment and the exposed group after the heat treatment process [11]. The characteristic peaks of the nanofiber films after heat treatment were 3316 and $3331 \mathrm{~cm}^{-1}$, and their hydrogen bond interaction was relatively stronger than that of the pure PVA, PVA/TP-9:1 and PVA/TP-8:2 nanofiber films. Moreover, a comparison of the infrared spectra with the nanofiber films without heat treatment indicated that the high temperature strengthened the intensities of the $\mathrm{O}-\mathrm{H}$ absorption peaks and increased the numbers of these hydrogen bonds, which is also consistent with the morphology results. 


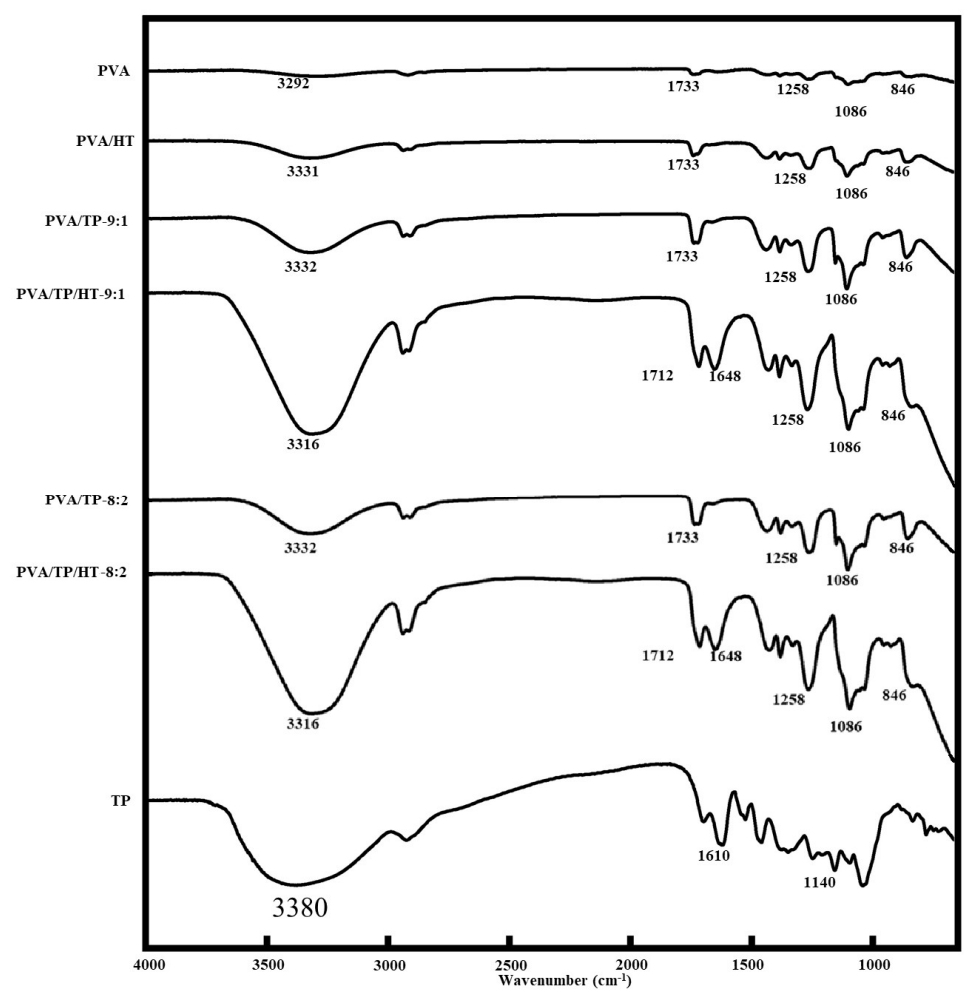

Figure 3. Fourier transform infrared (FTIR) spectra of PVA, PVA/HT, PVA/TP-8:2, PVA/TP/HT-8:2, PVA/TP-9:1, PVA/TP/HT-9:1, and TP nanofiber films.

\subsection{Water Resistance Analysis}

Although PVA and TPs have excellent safety, biocompatibility and biodegradability qualities, making them suitable for preparing food packaging materials, they also have good water solubility, meaning that the various properties of nanofiber films can easily be affected by environmental humidity. Therefore, our study aimed to decrease the material solubility by combining two methods of polymer blending and heat treatment (Figure 4a). The pure PVA nanofiber films dissolved in water immediately, which is similar to the results reported by Abdolmaleki et al. [8]. Although some hydroxyl groups of the PVA in the nanofiber films without heat treatment formed hydrogen bonds with the TP, which resulted in the existence of a strong hydrophilic hydroxyl group reduction and a decrease in the dissolution rate, the hydrogen bonds were not stable enough to prevent the material from dissolving in water. After heat treatment at high temperature, the solubility of the PVA nanofiber film decreased significantly because the thermal motion of the PVA molecule chain was promoted [12,13]. As the TP amount increased, more free hydroxyl groups in the PVA were lost to hydrogen bonding with the TP. In addition, the crystallization of materials was enhanced by the heat treatment, which changed the nanofiber films from a water-soluble to a water-absorbent and water-retentive material. When the mass ratio of the PVA/TP was 9:1, the nanofiber films were able to absorb 3.4 times their own weight in distilled water, but with no obvious swelling. The decrease in the nanofiber films' WS occurred primarily because the hydrogen bond interaction increased with an increase in the TP content. In addition, the water absorption rate generally decreased with a decrease in the number of hydrophilic hydroxyl groups (Table 1). Cano et al. [15] reported similar changes in water resistance in the nanofiber films carrying TPs. 

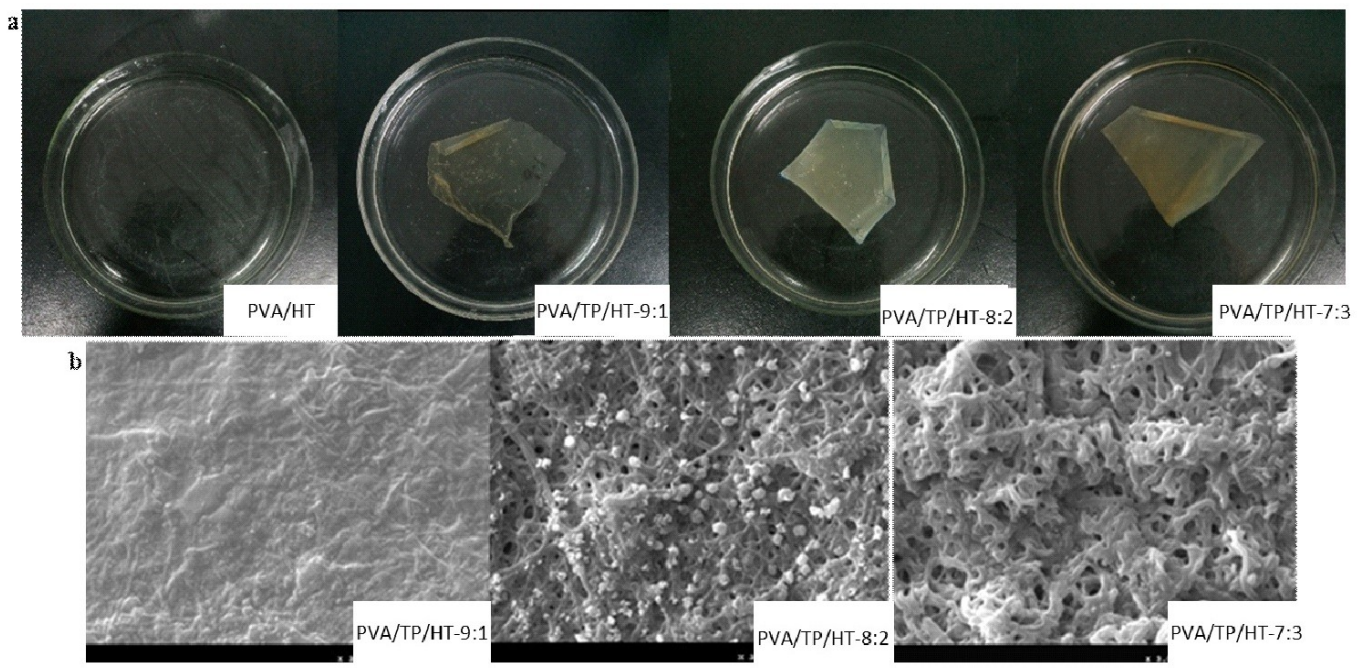

Figure 4. (a) Conditions of materials after immersion in water for $24 \mathrm{~h}$; (b) fiber morphology after $24 \mathrm{~h}$ of fiber immersion in water.

Table 1. Water absorption and dissolution rate results of each group of materials.

\begin{tabular}{ccc}
\hline Sample & Water Absorption (g/g) & Water Dissolution (\%) \\
\hline PVA & -- & $100 \pm 0^{\mathrm{a}}$ \\
PVA/TP-9:1 & -- & $100 \pm 0^{\mathrm{a}}$ \\
PVA/TP-8:2 & -- & $100 \pm 0^{\mathrm{a}}$ \\
PVA/TP-7:3 & - & $100 \pm 0^{\mathrm{a}}$ \\
PVA/HT & - & $100 \pm 0^{\mathrm{a}}$ \\
PVA/TP/HT-9:1 & $3.40 \pm 0.12^{\mathrm{a}}$ & $10.60 \pm 0.07^{\mathrm{b}}$ \\
PVA/TP/HT-8:2 & $2.40 \pm 0.15^{\mathrm{b}}$ & $3.93 \pm 0.10^{\mathrm{c}}$ \\
PVA/TP/HT-7:3 & $1.87 \pm 0.09^{\mathrm{c}}$ & $0 \pm 0.06^{\mathrm{d}}$ \\
\hline
\end{tabular}

Note: "- -" indicates immediate water solubility, and "-" indicates slow dissolution. Different letters between rows $\left({ }^{a-d}\right)$ indicate significantly different values $(p<0.05)$ according to Duncan's multiple range test, which is a post hoc comparison test. The data are presented as mean $\pm \mathrm{SD}(n=5)$.

\subsection{Effect of Water Immersion on the Fiber Morphology}

In order to further explore the effect of water soaking on the fiber morphology, 3000-fold magnification analysis was utilized to observe the morphology and structural changes after $24 \mathrm{~h}$ (Figure $4 \mathrm{~b}$ ). When the pure PVA nanofiber films were immersed in water, they appeared to rapidly dissolve. This could be attributed to the water-soluble polymer PVA qualities with a reticulate cubic structure and the large specific surface area of the nanofibers, which caused the porosity and the area of the film in contact with the water to increase. In contrast, the nanofiber film PVA/TP/HT-9:1 could not be dissolved after $24 \mathrm{~h}$. Although its water insolubility increased remarkably, the fibers were extensively dissolved, with only a few fibers remaining intact without pores. The properties of water resistance in film PVA/TP/HT-8:2 showed significant improvement. The membrane was slightly swollen from water absorption, and the fiber morphology was clearly visible with maintained inter-fiber pores, and only a few fibers were dissolved and destroyed. The nanofiber film PVA/TP/HT-7:3 showed the best properties of water resistance; the morphology was basically maintained and there was a slightly increase in the fiber diameter owing to water absorption. As a crosslinking effect due to the TP incorporation was present, this film formed hydrogen bonds between the TP and PVA molecules, resulting in improved mechanical properties because the heat treatment produced lower water solubility. Thus, the water-soluble material was converted to a water-absorbing material. 


\subsection{Mechanical Properties}

A previous experiment demonstrated that the water resistance was improved by heat treatment, indicating that the application of nanofiber films without heat treatment would be limited. Hence, to achieve the optimal formulation of PVA/TP nanofiber films for food packaging applications, the mechanical properties of the nanofiber films with heat treatment were explored as a function of their TP content. The influence of different levels of TP on the TS and EAB of PVA/TP nanofiber films is shown in Figure 5a,b. The TS of the nanofiber films, which was increased to $53.78 \pm 2.12 \mathrm{MPa}$, was four to eight times that of the pure PVA nanofiber film at $7.12 \pm 0.25 \mathrm{MPa}$. As indicated by FTIR, the increased TP content led to strong interactions between the functional groups of the TPs and the hydroxyl groups of the PVA molecules through hydrogen interaction, indicated by the FTIR, which resulted in more compact structures and thus gradually improved the TS of the PVA/TP nanofiber films gradually [37]. As shown in Figure 5b, the EAB of the pure PVA nanofiber films was $74.52 \%$ $\pm 4.57 \%$. Additionally, the EAB of the PVA/TP nanofiber films increased with an increase in the TP content, and reached a maximum of $105.24 \% \pm 2.87 \%$ at a mass PVA:TP ratio of $9: 1$, and then visibly decreased at higher TP concentrations [15]. This could be attributed to the strong hydrogen interaction, which hindered the chain movement and resulted in lower plasticizing and nanofiber film flexibility; these qualities were also demonstrated by the nanofiber film morphology (Figure 1a-f).
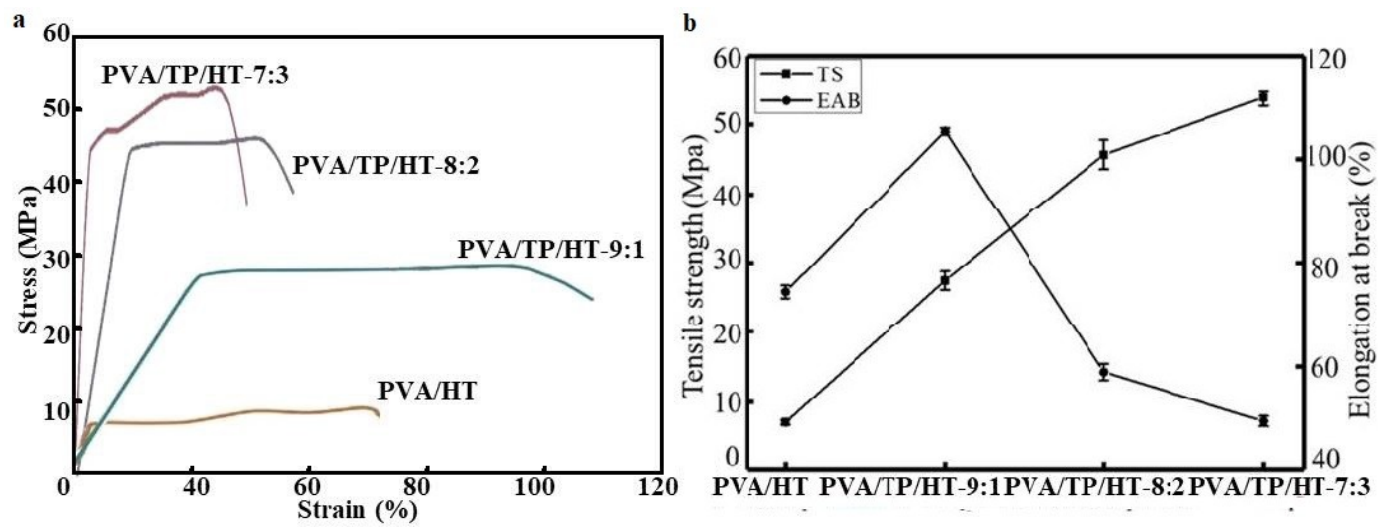

Figure 5. (a) Stress-strain curves; (b) trend diagram of tensile strength (TS) and elongation at break (EAB) of PVA/HT, PVA/TP/HT-7:3, PVA/TP/HT-8:2, and PVA/TP/HT-9:1 nanofiber films.

These results indicate that mechanical properties of the nanofiber films were improved, particularly for the TS and EAB values, which were achieved by blending with TPs. Cano et al. [15] reported a similar finding. These results provide the optimal formulation of PVA and TPs to satisfy the requirements of water resistance and mechanical properties in materials used for food packaging applications.

DPPH was used because of its characteristic absorption at $517 \mathrm{~nm}$ measured in a radical scavenging study for nanofiber films incorporated with TP. The decline in absorption was viewed as a measure of the extent of radical scavenging [38]. The DPPH radical-scavenging activity in the nanofiber films increased significantly as the TP content increased, as shown in Figure 6; this result is consistent with that reported by Liu et al. [39]. The pure PVA nanofiber films exhibited a slight DPPH radical scavenging activity of $13.75 \% \pm 4.11 \%$ owing to the presence of hydrogen on the carbon atom with hydroxyl groups, which could indicate its antioxidant capacity. The addition of TPs increased the DPPH radical-scavenging activity of PVA/TP/HT-9:1 film to $53.83 \% \pm 3.37 \%$. Moreover, when the mass ratio of PVA:TP ratio was 7:3, the nanofiber films showed a DPPH radical-scavenging activity that reached its maximum at $64.83 \% \pm 5.21 \%$; this indicates an approximately five-fold improvement compared with that in the PVA nanofiber films. When immersed in water, the PVA nanofiber films swelled at the gaps in the nanofiber film, which resulted in a looser network structure, which in turn decreased the constraining force of the polymer matrix and promoted the release of TPs, thereby increasing the capacity for DPPH radical-scavenging activity. Although the increase in TP content was multiplied in PVA/TP/HT-9:1 and 
PVA/TP/HT-7:3, the solubility of the nanofiber films decreased. This would lead to a slow increase in antioxidant activity because the release of TPs was incomplete $[23,40]$. Recently, the slow-release effect of nanofibers has shown a positive effect for drug delivery in biomaterials. Therefore, the promotional result of this slow-release effect of the nanofiber film on the antioxidant and antibacterial properties of films merits further study in the application of food packaging for preservation.

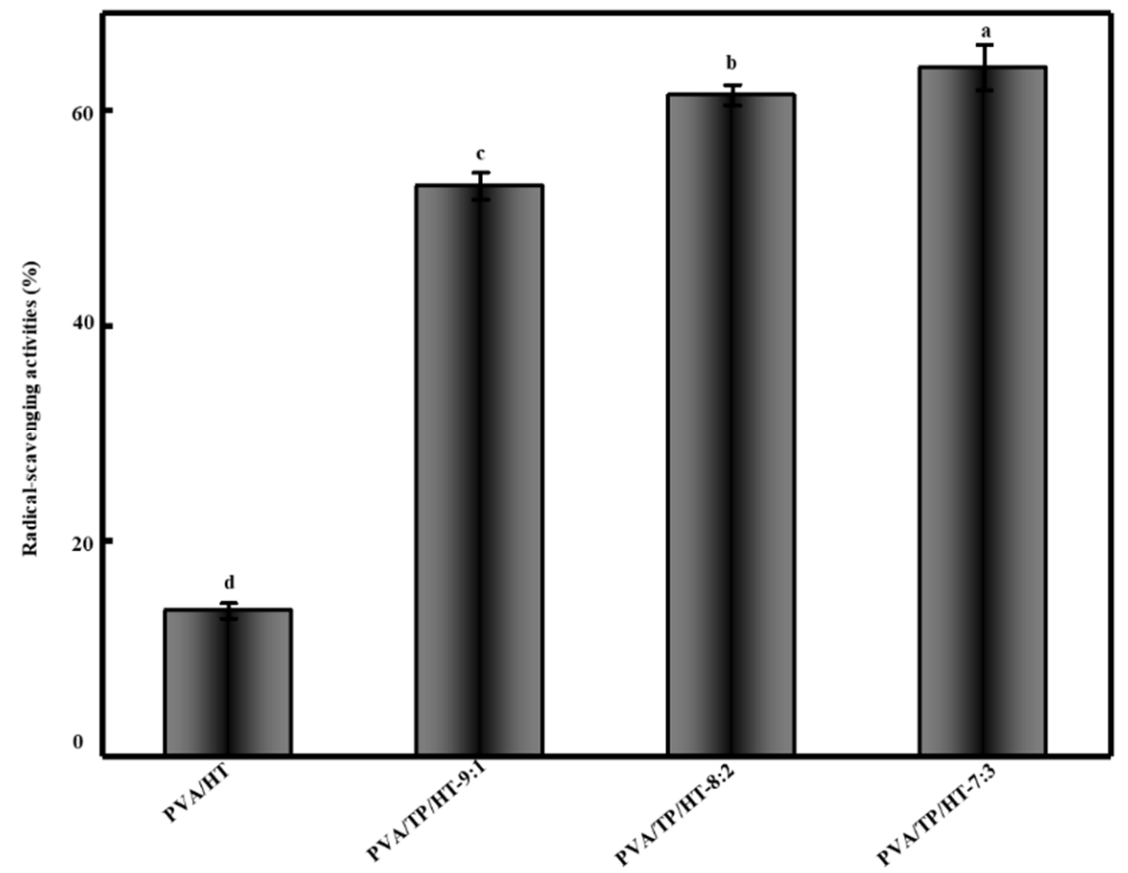

Figure 6. Trend of radical-scavenging activities. Data followed by different lowercase letters were significantly different $(p<0.05)$ when comparing the radical-scavenging activities of nanofiber film.

\subsection{Color and Transparency of the Films}

Color attributes are significant for nanofiber films because they have a direct effect on consumer acceptability and the appearance of the packaged product [41]. According to the standard white plate $\left(L^{*}=90.07 \pm 0.93, a^{*}=2.94 \pm 0.40, b^{*}=-5.33 \pm 0.28\right)$, the effects of the TP content and heat treatment on the nanofiber film color difference $(\Delta E)$ are presented in Table 2 . The values of $L^{*}, a^{*}$ and $b^{*}$ in the pure PVA nanofiber films were $96.37 \pm 0.25,3.59 \pm 0.05$ and $-2.87 \pm 0.10$, respectively. However, Xie et al. [42] reported these values to be $92.59 \pm 0.04,0.51 \pm 0.04$ and $-6.05 \pm 0.04$, respectively, which suggests that the nanofiber films are more brightly colored than the casting films. In comparing PVA and PVA/TP-9:1, the values of $L^{*}$ and $a^{*}$ decreased, which indicates that the nanofiber films became darker as the TPs were incorporated into the nanofiber films. In addition, the color of the nanofiber films showed a tendency toward a yellowish hue, as illustrated by the increase in the $b^{*}$ value from $-2.87 \pm$ 0.10 for the pure PVA nanofiber films to $1.79 \pm 0.09$ for the nanofiber films with TP. The values of $\Delta \mathrm{E}, a^{*}$, and $b^{*}$ increased with an increase in the TP content, suggesting an increase in the yellowish trends in the nanofiber films. A similar result was also reported by Dou et al. [43]. Moreover, it can be observed that the values of $L^{*}$ were reduced, although those of $a^{*}, b^{*}$ and $\Delta E$ increased $31 \%$ compared with that of the film after heat treatment (Table 2), and showed a tendency towards a brownish color; these results are in good agreement with the those reported by Bora et al. [44]. Table 2 also clearly shows that significant differences were observed among the various films prepared at different concentrations including or excluding heat treatment. This could have caused the color difference of the TPs. More TPs incorporated into the films reduced their transparency. Moreover, opacity was observed to significantly change, with higher values shown in the films without heat treatment. This could be attributed to gradual TP oxidation in the heat treatment process with an increase in temperature [45]. 
Table 2. Effect of the heat treatment and incorporation of TP on the color and transparency of nanofiber films.

\begin{tabular}{cccccc}
\hline Film & $\boldsymbol{L}^{*}$ & $\boldsymbol{a}^{*}$ & $\boldsymbol{b}^{*}$ & $\boldsymbol{\Delta E}$ & $\begin{array}{c}\text { Opacity } \\
(\mathbf{A 6 0 0 / m m})\end{array}$ \\
\hline PVA & $96.37 \pm 0.25^{\mathrm{a}}$ & $3.59 \pm 0.05^{\mathrm{a}}$ & $-2.87 \pm 0.10^{\mathrm{g}}$ & $6.80 \pm 0.27^{\mathrm{f}}$ & $65.22 \pm 4.31^{\mathrm{A}}$ \\
PVA/HT & $95.90 \pm 0.73^{\mathrm{a}}$ & $3.97 \pm 0.86^{\mathrm{a}}$ & $1.46 \pm 0.46^{\mathrm{f}}$ & $9.01 \pm 0.66^{\mathrm{d}}$ & $57.61 \pm 4.08^{\mathrm{B}}$ \\
PVA/TP-9:1 & $90.58 \pm 0.19^{\mathrm{b}}$ & $0.44 \pm 0.11^{\mathrm{c}}$ & $1.79 \pm 0.09^{\mathrm{f}}$ & $7.57 \pm 0.08^{\text {ef }}$ & $48.37 \pm 3.68^{\mathrm{C}}$ \\
PVA/TP/HT-9:1 & $78.61 \pm 0.82^{\mathrm{b}}$ & $5.24 \pm 0.25^{\mathrm{a}}$ & $14.03 \pm 0.96^{\mathrm{c}}$ & $22.61 \pm 1.26^{\mathrm{c}}$ & $40.45 \pm 3.17^{\mathrm{D}}$ \\
PVA/TP-8:2 & $90.72 \pm 0.04^{\mathrm{b}}$ & $0.86 \pm 0.09^{\mathrm{bc}}$ & $2.76 \pm 0.11^{\mathrm{e}}$ & $8.38 \pm 0.12^{\mathrm{de}}$ & $34.59 \pm 2.91^{\mathrm{E}}$ \\
PVA/TP/HT-8:2 & $76.69 \pm 1.25^{\mathrm{c}}$ & $5.57 \pm 0.22^{\mathrm{a}}$ & $17.92 \pm 0.40^{\mathrm{b}}$ & $26.96 \pm 0.24^{\mathrm{b}}$ & $28.14 \pm 2.52^{\mathrm{F}}$ \\
PVA/TP-7:3 & $90.65 \pm 0.47^{\mathrm{b}}$ & $1.30 \pm 0.33^{\mathrm{b}}$ & $3.50 \pm 0.66^{\mathrm{d}}$ & $9.01 \pm 0.62^{\mathrm{d}}$ & $22.78 \pm 2.11^{\mathrm{G}}$ \\
PVA/TP/HT-7:3 & $76.36 \pm 0.86^{\mathrm{d}}$ & $6.58 \pm 0.30^{\mathrm{a}}$ & $20.76 \pm 0.16^{\mathrm{a}}$ & $29.70 \pm 0.48^{\mathrm{a}}$ & $18.47 \pm 2.02^{\mathrm{H}}$ \\
\hline
\end{tabular}

Note: Different letters between rows $\left.{ }^{\left({ }^{-}-\mathrm{f}\right.}\right)$ and between lines $\left({ }^{\mathrm{A}-\mathrm{H}}\right)$ indicate significantly different values $(p<0.05)$ according to Duncan's multiple range test, which is a post hoc comparison test. The data are presented as mean \pm SD $(n=5)$.

\subsection{Antimicrobial Analysis}

The antibacterial effects on E. coli and S. aureus in the pure PVA nanofiber films and the nanofiber films of various PVA:TP mass ratios are shown in Figure 7. The pure PVA nanofiber films exhibited no visible inhibitory effect on E. coli or S. aureus, whereas the incorporation of TPs remarkably increased the antibacterial effects. In addition, the inhibition rate increased remarkably for both strains with an increase in the TP content. The results revealed that the antibacterial activity of E. coli and S. aureus increased considerably and reached maximum levels at $82.48 \% \pm 2.12 \%$ and $86.25 \% \pm 2.32 \%$, respectively. These results further demonstrate that the main antibacterial ingredients were the TPs, and that the inhibitory effect of the nanofiber films was more efficient for S. aureus than E. coli. These findings, which are in agreement with the results reported in the literature [45], likely occurred because the antibacterial mechanism of TPs destroyed the cell permeability in the agglutination of the membrane lipid and protein conformation and damaged the cell membrane of both strains. This led to a disordered metabolism and the leakage of the cell contents, thereby causing cell death and inhibiting growth. Moreover, the TPs exhibited stronger bacteriostatic and antibacterial activities against gram-positive $S$. aureus than gram-negative E. coli. This can be attributed to the existence of lipopolysaccharides, which caused the structure of the cell walls of the latter species to be more compact and resistant to TPs. Finally, the presence of catechins and flavonoids as TP components resulted in broad-spectrum antibacterial properties; these findings are similar to those reported by Taguri et al. [46]. 


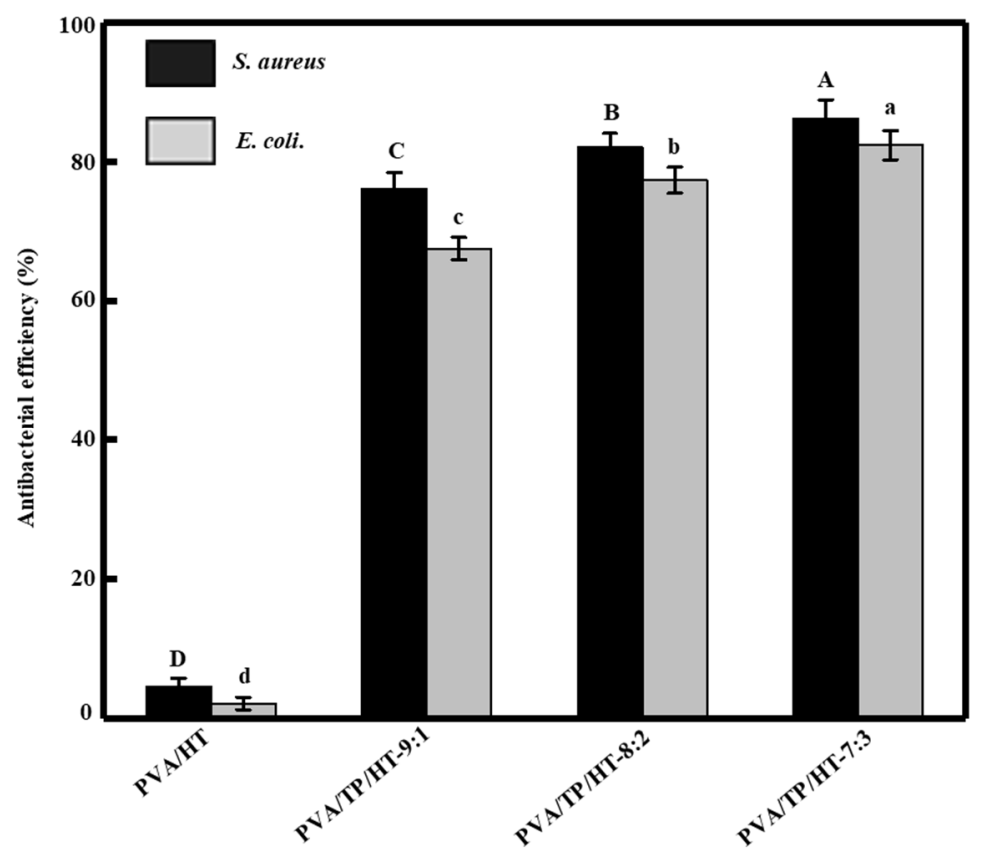

Figure 7. Antibacterial efficiency on E. coli and S. aureus in the nanofiber films. The data followed by different uppercase (lowercase) letters were significantly different $(p<0.05)$ when comparing the antibacterial efficiency of nanofibers on S. aureus (E. coli).

\section{Conclusions}

In this study, PVA/TP nanofiber films were prepared by electrospinning, and the effects of heat treatment and TP incorporation on their structural and physical properties as well as their water resistance were elucidated. The results showed that the presence of TPs enhanced the water resistance of the nanofiber films and produced a more compact network structure and better morphology after heat treatment. Moreover, the water-soluble material was converted to a water-absorbing material owing to the formation of hydrogen bonds between the TP and PVA molecules, which were increased by the heat treatment. Furthermore, the addition of TPs produced PVA/TP nanofiber films with four to eight times greater TS than the pure PVA film, which was increased to $53.78 \pm 2.12 \mathrm{MPa}$. In addition, the antioxidant activity reached its maximum level at $64.83 \% \pm 5.21 \%$, and the antibacterial activity of E. coli and S. aureus increased to maxima of $82.48 \% \pm 2.12 \%$ and $86.25 \% \pm 2.32 \%$ respectively. Our study described a potential replacement for synthetic materials and produced practical food packaging with acceptable bioactivity, fresh-keeping ability and biodegradability.

Author Contributions: J.L. wrote the manuscript, J.L. is the guarantor, D.Z. developed the original idea and the protocol, abstracted and analyzed data, Z.D. collected the data, A.J. adjusted the experimental scheme, and G.X. revised the manuscript. All authors have read and agreed to the published version of the manuscript.

Funding: This research was funded by Chongqing Engineering Technology Research Center for Light Alloy and Processing Fund (GCZX201801), and Science and Technology Research Program of Chongqing Municipal Education Commission (KJQN201801202).

Conflicts of Interest: The authors declare no conflict of interest.

\section{References}

1. Castro López, M.D.M.; López de Dicastillo, C.; López Vilariño, J.M.; González Rodríguez, M.V. Improving the capacity of polypropylene to be used in antioxidant active films: Incorporation of plasticizer and natural antioxidants. J. Agric. Food Chem. 2013, 61, 62-70. [CrossRef] [PubMed]

2. Cömert, E.D.; Gökmen, V. Evolution of food antioxidants as a core topic of food science for a century. Food Res. Int. 2018, 105, 76-93. [CrossRef] [PubMed] 
3. Sagnelli, D.; Kirkensgaard, J.J.; Giosafatto, C.V.L.; Ogrodowicz, N.; Kruczała, K.; Mikkelsen, M.S.; Maigret, J.E.; Lourdin, D.; Mortensen, K.; Blennow, A. All-natural bio-plastics using starch-betaglucan composites. Carbohydr. Polym. 2017, 172, 237-245. [CrossRef] [PubMed]

4. Zhuang, C.; Jiang, Y.; Zhong, Y.; Zhao, Y.; Deng, Y.; Yue, J.; Wang, D.; Jiao, S.; Gao, H.; Chen, H.; et al. Development and characterization of nano-bilayer films composed of polyvinyl alcohol, chitosan and alginate. Food Control 2018, 86, 191-199. [CrossRef]

5. Lim, M.; Kim, D.; Seo, J. Enhanced oxygen-barrier and water-resistance properties of poly (vinyl alcohol) blended with poly (acrylic acid) for packaging applications. Polym. Int. 2016, 65, 400-406. [CrossRef]

6. Yang, J.M.; Fan, C.S.; Wang, N.C.; Chang, Y.H. Evaluation of membrane preparation method on the performance of alkaline polymer electrolyte: Comparison between poly (vinyl alcohol)/chitosan blended membrane and poly (vinyl alcohol)/chitosan electrospun nanofiber composite membranes. Electrochim. Acta 2018, 266, 332-340. [CrossRef]

7. Abdolmaleki, A.; Mallakpour, S.; Karshenas, A. Synthesis and characterization of new nanocomposites films using alanine-cu-functionalized graphene oxide as nanofiller and PVA as polymeric matrix for improving of their properties. J. Solid State Chem. 2017, 253, 398-405. [CrossRef]

8. Pirzada1, T.; Shah, S.S. Water-Resistant Poly (vinyl alcohol)-Silica Hybrids through Sol-Gel Processing. Chem. Eng. Technol. 2014, 37, 620-626. [CrossRef]

9. Noh, T.; Bando, Y.; Ota, K.; Sasaki, S.; Suzuki, A. Tear force of physically crosslinked poly (vinyl alcohol) gels with different submicrometer-scale network structures. J. Appl. Polym. Sci. 2015, 132, 1-6. [CrossRef]

10. Liu, F.; Ni, Q.Q.; Murakami, Y. Preparation of magnetic polyvinyl alcohol composite nanofibers with homogenously dispersed nanoparticles and high water resistance. Text. Resm. J. 2013, 83, 510-518. [CrossRef]

11. Lee, K.; Lee, S. Electrospun zinc oxide/poly (vinyl alcohol) nanofibrous membranes: In vitro and wear trial evaluation of antimicrobial activity. Text. Res. J. 2015, 85, 1999-2008. [CrossRef]

12. Xie, Z.L.; Hoang, M.; Ng, D.; Doherty, C.; Hill, A.; Gray, S. Effect of heat treatment on pervaporation separation of aqueous salt solution using hybrid PVA/MA/TEOS membrane. Sep. Purif. Technol. 2014, 127, 10-17. [CrossRef]

13. Gao, Q.; Luo, J.; Wang, X.Y.; Gao, C.X.; Ge, M.Q. Novel hollow $\alpha-\mathrm{Fe}_{2} \mathrm{O}_{3}$ nanofibers via electrospinning for dye adsorption. Nanoscale Res. Lett. 2015, 10, 176-184. [CrossRef] [PubMed]

14. Cano, A.I.; Cháfer, M.; Chiralt, A.; Martínez, C.G. Physical and microstructural properties of biodegradable films based on pea starch and PVA. J. Food Eng. 2015, 167, 59-64. [CrossRef]

15. Sahin, A. The development of Speek/Pva/Teos blend membrane for proton exchange membrane fuel cells. Electrochim. Acta 2018, 271, 127-136. [CrossRef]

16. Liu, G.; Zhang, L.J.; Mao, S.; Rohani, S.; Ching, C.; Lu, J. Zwitterionic chitosan-silica-PVA hybrid ultrafiltration membranes for protein separation. Sep. Purif. Technol. 2015, 152, 55-63. [CrossRef]

17. Priya, V.; Vikas, P. Synthesis and characterization of crosslinked gellan/PVA nanofibers for tissue engineering application. Mat. Sci. Eng. C Mater. 2016, 67, 304-312. [CrossRef]

18. Yahyaei, H.; Shahab, S.; Sheikhi, M.; Filippovich, L.; Almodarresiyeh, H.A.; Kumar, R.; Dikusar, E.; Borzehandaani, M.Y.; Alnajjar, R. Anisotropy (optical, electrical and thermal conductivity) in thin polarizing films for UV/Vis regions of spectrum: Experimental and theoretical investigations. Spectrochim. Acta A 2018, 192, 343-360. [CrossRef]

19. Lan, W.; Zhang, R.; Ahmed, S.; Qin, W.; Liu, Y. Effects of various antimicrobial polyvinyl alcohol/tea polyphenol composite films on the shelf life of packaged strawberries. LWT 2019, 113, 108297. [CrossRef]

20. Wang, Y.; Zhang, R.; Qin, W.; Dai, J.; Zhang, Q.; Lee, K.; Liu, Y. Physicochemical properties of gelatin films containing tea polyphenol-loaded chitosan nanoparticles generated by electrospray. Mater. Des. 2020, 185, 108277. [CrossRef]

21. Li, C.; Lou, T.; Yan, X.; Long, Y.Z.; Cui, G.; Wang, X. Fabrication of pure chitosan nanofibrous membranes as effective absorbent for dye removal. Int. J. Biol. Macromol. 2018, 106, 768-774. [CrossRef] [PubMed]

22. Laha, A.; Sharma, C.S.; Majumdar, S. Sustained drug release from multi-layered sequentially crosslinked electrospun gelatin nanofiber mesh. Mater. Sci. Eng. C 2017, 76, 782-786. [CrossRef] [PubMed]

23. Hee, K.D.; Wook, K.H. Advanced electrospinning using circle electrodes for freestanding PVDF nanofiber film fabrication. Appl. Surf. Sci. 2018, 455, 251-257. [CrossRef] 
24. Liu, Y.; Wang, S.; Lan, W.; Qin, W. Fabrication and testing of PVA/Chitosan bilayer films for strawberry packaging. Coatings 2017, 7, 109. [CrossRef]

25. Ye, Q.; Han, Y.; Zhang, J.; Zhang, W.; Xia, C.; Li, J. Bio-based films with improved water resistance derived from soy protein isolate and stearic acid via bioconjugation. J. Clean. Prod. 2019, 214, 125-131. [CrossRef]

26. ASTM D638 Standard Test Method for Tensile Properties of Plastics; ASTM International: West Conshohocken, PA, USA, 2014.

27. ASTM Standard 882 Standard Test Method for Tensile Properties of Thin Plastic Sheeting; ASTM International: West Conshohocken, PA, USA, 2014.

28. Jahed, E.; Khaledabad, M.A.; Bari, M.R.; Almasi, H. Effect of cellulose and lignocellulose nanofibers on the properties of Origanum vulgare, ssp. gracile, essential oil-loaded chitosan films. React. Funct. Polym. 2017, 117, 70-80. [CrossRef]

29. Zhang, C.; Wang, Z.; Li, Y.; Yang, Y.; Ju, X.; He, R. The preparation and physiochemical characterization of rapeseed protein hydrolysate-chitosan composite films. Food Chem. 2019, 272, 694-701. [CrossRef]

30. Abdalrazeq, M.; Giosafatto, C.V.L.; Esposito, M.; Fenderico, M.; Di Pierro, P.; Porta, R. Glycerol-plasticized films obtained from whey proteins denatured at alkaline $\mathrm{pH}$. Coatings 2019, 9, 322. [CrossRef]

31. Liu, Y.; Wang, S.; Lan, W.; Qin, W. Fabrication of polylactic acid/carbon nanotubes/chitosan composite fibers by electrospinning for strawberry preservation. Int. J. Biol. Macromol. 2019, 121, 1329-1336. [CrossRef]

32. Lei, Y.L.; Wu, H.J.; Jiao, C. Investigation of the structural and physical properties, antioxidant and antimicrobial activity of pectin-konjac glucomannan composite edible films incorporated with tea polyphenol. Food Hydrocoll. 2019, 94, 128-135. [CrossRef]

33. Liu, Y.W.; Wang, S.Y.; Lan, W.J. Fabrication of antibacterial chitosan-PVA blended film using electrospray technique for food packaging applications. Int. J. Biol. Macromol. 2018, 107, 848-854. [CrossRef] [PubMed]

34. Yu, Z.; Li, B.; Chu, J.; Zhang, P. Silica in situ enhanced PVA/chitosan biodegradable films for food packages. Carbohydr. Polym. 2017, 184, 214-220. [CrossRef] [PubMed]

35. Ningaraju, S.; Prakash, A.P.G.; Ravikumar, H.B. Studies on free volume controlled electrical properties of $\mathrm{PVA} / \mathrm{NiO}$ and $\mathrm{PVA} / \mathrm{TiO}_{2}$ polymer nanocomposites. Solid State Ion. 2018, 320, 132-147. [CrossRef]

36. Biao, Y.; Yuxuan, C.; Qi, T.; Ziqi, Y.; Yourong, Z.; McClements, D.J.; Chongjiang, C. Enhanced performance and functionality of active edible films by incorporating tea polyphenols into thin calcium alginate hydrogels. Food Hydrocoll. 2019, 97, 105-197. [CrossRef]

37. Chowdhury, S.C.; Gillespie, J.W. A molecular dynamics study of the effects of hydrogen bonds on mechanical properties of Kevlar ${ }^{\circledR}$ crystal. Comp. Mater. Sci. 2018, 148, 286-300. [CrossRef]

38. Gu, H.; Chen, X.; Zhou, X.; Parsaee, Z. Ultrasound-assisted biosynthesis of CuO-NPs using Brown alga cystoseira trinodis: Characterization, photocatalytic AOP, DPPH scavenging and antibacterial investigations. Ultrason. Sonochem. 2018, 41, 109-119. [CrossRef] [PubMed]

39. Liu, F.; Avena-Bustillos, R.J.; Chiou, B.S.; Li, Y.; Ma, Y.; Williams, T.G.; Wood, D.F.; McHugh, T.H.; Zhong, F. Controlled-release of tea polyphenol from gelatin films incorporated with different ratios of free/nanoencapsulated tea polyphenols into fatty food simulants. Food Hydrocoll. 2017, 62, 212-221. [CrossRef]

40. Moydeen, A.M.; Padusha, M.S.A.; Aboelfetoh, E.F.; Al-Deyab, S.S.; El-Newehy, M.H. Fabrication of electrospun poly (vinyl alcohol)/Dextran nanofibers via emulsion process as drug delivery system: Kinetics and in vitro release study. Int. J. Biol. Macromol. 2018, 116, 1250-1259. [CrossRef]

41. Kakaei, S.; Shahbazi, Y. Effect of chitosan-gelatin film incorporated with ethanolic red grape seed extract and Ziziphora clinopodioides, essential oil on survival of Listeria monocytogenes, and chemical, microbial and sensory properties of minced trout fillet. LWT-Food Sci. Technol. 2016, 72, 432-438. [CrossRef]

42. Xie, M.; Wang, J.; Zhao, H. A PVA film for detecting lipid oxidation intended for food application. Sensor. Actuat. B-Chem. 2018, 273, 260-263. [CrossRef]

43. Dou, L.; Li, B.; Zhang, K.; Chu, X.; Hou, H. Physical properties and antioxidant activity of gelatin-sodium alginate edible films with tea polyphenol. Int. J. Biol. Macromol. 2018, 118, 1377-1383. [CrossRef] [PubMed]

44. Bora, A.F.M.; Ma, S.; Li, X.; Liu, L. Application of microencapsulation for the safe delivery of green tea polyphenols in food systems: Review and recent advances. Food Res. Int. 2018, 105, 241-249. [CrossRef] [PubMed] 
45. An, B.J.; Kwak, J.H.; Son, J.H.; Park, J.M.; Lee, J.Y.; Jo, C.; Byun, M.W. Biological and anti-microbial activity of irradiated green tea polyphenols. Food Chem. 2004, 88, 549-555. [CrossRef]

46. Taguri, T.; Tanaka, T.; Kouno, I. Antimicrobial activity of 10 different plant polyphenols against bacteria causing food-borne disease. Biol. Pharm. Bull. 2004, 27, 1965-1969. [CrossRef] [PubMed]

(C) 2020 by the authors. Licensee MDPI, Basel, Switzerland. This article is an open access article distributed under the terms and conditions of the Creative Commons Attribution (CC BY) license (http://creativecommons.org/licenses/by/4.0/). 